\title{
A novel test method for quantifying surface tack of polypropylene compound surfaces
}

\author{
U. D. Çakmak ${ }^{1}$, G. Grestenberger ${ }^{2 *}$, Z. Major $^{1}$ \\ ${ }^{1}$ Johannes Kepler University Linz, Institute of Polymer Product Engineering, Altenbergerstr. 69, 4040 Linz, Austria \\ ${ }^{2}$ Borealis Polyolefine GmbH, Innovation Headquarters, St-Peterstraße 25, 4021 Linz, Austria
}

Received 1 April 2011; accepted in revised form 2 June 2011

\begin{abstract}
While adhesiveness is required for polymer surfaces in special applications, tacky surfaces are generally undesirable in many applications like automotive interior parts. The tackiness of polymer surface results from a combination of composition and additivation, and it can change significantly in natural or accelerated ageing. Since there is no established, uniform method to characterize surface tack, the major focus of the present work was on the development of an objective quantification method. A setup having a soft die tip attached to a standard tensile tester was developed aiming for correlation to the human sense of touch. Three different model thermoplastic polyolefin (TPO) compound formulations based on a high-impact isotactic polypropylene (iPP) composition with varying amounts and types of anti-scratch additives were used for these investigations. As the surface tack phenomenon is related to ageing and weathering, the material's examination was also performed after various intervals of weathering. The developed method allows a fast assessment of the effect of polymer composition variations and different additive formulations on surface tack and gives identical rankings as the standardized haptic panel.
\end{abstract}

Keywords: material testing, industrial applications, surface tack, polypropylene, haptic properties

\section{Introduction}

Due to their versatility and easy shaping properties, polymers have successively replaced classic materials such as wood and leather for automobile interiors since the middle of the last century. Especially thermoplastic polyolefin (TPO) compounds based on isotactic polypropylene (iPP) as matrix polymer are widely used as interior parts (e.g. instrument panels, pillar trims, door claddings) in the automotive industry. The property spectrum of this polymer class is very broad and can be tailored by varying the type and content of elastomers and fillers as well as the use of special additives [1-8]. The material can be adjusted to achieve desired properties with regard to the original part manufacturer (OEM) specifications, with the key material properties con- sidered for interior applications illustrated in Figure 1.

The OEM specifications require a balanced mechanical performance in combination with a material

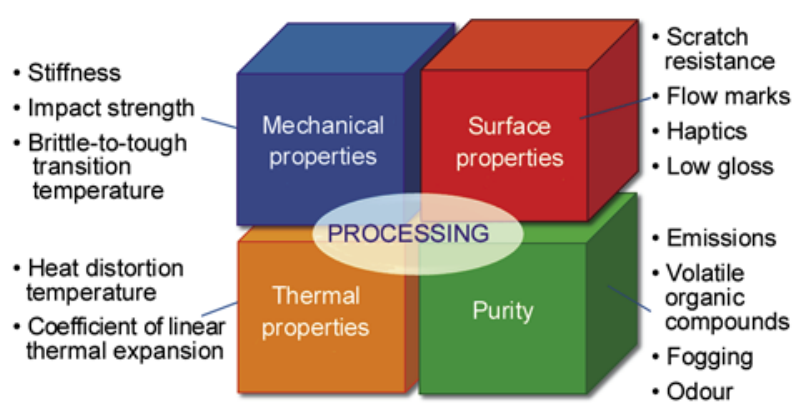

Figure 1. Illustration of the considered material specifications for plastics for automotive interior applications 
surface offering high scratch resistance, low gloss, and good 'surface feel' or haptics [9]. Haptic properties refer to the subjective surface impression during touching and qualitatively rank between completely non-tacky surfaces and tacky surfaces generally characterized by a high level of adhesiveness [10]. Although adhesiveness might be required in many applications, like adhesive tapes or notes, it is highly undesirable for automotive interior parts. In some cases, OEMs observed tackiness on part surfaces after weathering (elevated temperature and UV-irradiation, among other parameters) and assumed that the migration of incorporated additives is a main driver for this phenomenon. The migratory additives in TPO-compounds include antioxidants, UV-stabilizers, anti-scratch additives and mould release agents. Other possible sources of surface adhesion are amorphous low molecular weight fractions of the polymer composition itself [11].

A major concern around the surface tack phenomenon is the lack of an appropriate test method and standardized test equipment or methodology to characterize this important phenomenon. It can hardly be compared to tack measurements for adhesives $[12,13]$ because the respective tack forces are orders of magnitude lower than for e.g. for pressuresensitive adhesives while the complex detachment phenomena like cavitation [14] will not play a role. For pure elastomers (like natural rubber) surface tack measurement is an established method and mostly related to the quantification of adhesive forces $[10,15]$ with short contact time measurements playing an important role $[16,17]$. For polymers, such measurements have been developed for the film area [18] but rather with a focus on selfadhesion as desired for cling films. Rigid surfaces not subjected to a coating or painting process have mostly been neglected in this respect so far.

In the automotive area, OEMs and material suppliers have previously designed their own methods to assess tackiness. Most of these techniques make use of haptic reference scales or describe the corresponding sensory perception $[9,12,19]$. One example is the 'Sensotact tactile reference frame' (manufacturer: Cemas, Besançon, France). This reference scale consists of a set of ten descriptors, each made up of five reference parts in ascending order of sense of touch intensity. Each descriptor represents a different haptic sense. In this way, Sensotact distinguishes ten surface characteristics, which are determined according to specific finger movements - orthogonal or tangential - across the surface. To determine the tackiness of a surface, the index, middle, and ring fingers are lightly pressed onto the surface at an angle of about $15^{\circ}$. The resistance felt during the subsequent lifting of the fingers is regarded as a measure for tack [20]. Unfortunately, these methods generally lack reproducibility as they are based on testers' impressions of surface tack which are quite subjective, time-consuming and difficult to compare between laboratories.

An attempt to really quantify the tackiness of plastic surfaces was made by Huber and Solera [21] in adapting a film block tester normally used to determine the block strength or lubricity of plastic films. In order to assess the tackiness of artificially aged plates, low density polyethylene (LDPE) films were pressed onto the still-warm plates $(30$ min with a load of $5 \mathrm{~kg}$ ). After a defined conditioning period, the films were peeled off with the block tester, and the adhesive force recorded. With this setup it could be shown that under corresponding UV radiation of the components, the decomposition products of erucamide resulted in higher film adhesion. No attempt was made to relate the measured forces to human perception, and the film block tester only permitted a differentiation of adhesive forces up to $21 \mathrm{~N}$. All samples with higher values were classified as 'bad'. The target of the present study was therefore to develop a test setup and surface tack method suitable for the characterization of rigid surfaces typical for automotive interiors, the results of which should be related to those of a haptic panel, i.e. human perception. An important factor in designing the experiment should be a realistic contact time, avoiding both the very short contact typical for elastomer testing ( $0.1 \mathrm{~s}$, see [17]) and the very long times for film block testing (30 min, see [21]).

\section{Experimental work}

\subsection{Materials and specimen preparation}

Three different model TPO-compound formulations based on a high-impact ethylene-propylene copolymer from sequential copolymerization in a reactor cascade [22] were used for these investigations. The compounds were formulated with varying amounts and types of slip agents to reduce 
scratch sensitivity, while the other constituents (base resin, talc, antioxidants and UV-stabilizer) were kept constant. The base polymer was a commercial grade having a melt flow rate (melt flow rate (MFR) $230^{\circ} \mathrm{C} / 2.16 \mathrm{~kg}$, ISO 1133 ) of $18 \mathrm{~g} / 10 \mathrm{~min}$ and a total ethylene content of $20 \mathrm{wt} \%$, to which $11 \mathrm{wt} \%$ high density polyethylene (HDPE) (density $964 \mathrm{~kg} / \mathrm{m}^{3}$ ) and $17 \mathrm{wt} \%$ talc (Steamic T1CA, Luzenac, France) as well as a stabilization package and carbon black were added. One migratory additive, oleamide (Crodamide OR, Croda, Italy) at $0.15 \mathrm{wt} \%$ was compared to the neat material and a silicone (Tegomer Antiscratch 100, Evonik, Germany) as non-migratory additive at $2.0 \mathrm{wt} \%$.

The stickiness test was performed on injection moulded 'VW' multigrain plaques (see Figure 2) with a film gate using the grain K29 to characterize the tackiness. The K29 surface is defined as a grain with a grain depth of $0.01 \mathrm{~mm}$, and a minimum draft angle of $1^{\circ}$ for ejection from the injection moulding tool [23]. The section with this grain was cut out from the plaque with a bench shear.

As the surface tack phenomenon is often considered as a consequence of weathering conditions, the material examination was performed after various intervals of weathering. The specimens were faced around a light source in an environmental chamber (WeatherOmeter Ci4000, Atlas Material Testing Technology $\mathrm{GmbH}$; Linsengericht, Germany) and artificially weathered. The Kalahari weathering condition in dry and hot climate was performed, which is a well-known test in the automotive industry [24]. The weathering conditions of the chamber were:

- light source: Xenon arc light

- filter: Pyrex S

- black standard temperature: $90^{\circ} \mathrm{C}$

- chamber temperature in the dry phase: $50^{\circ} \mathrm{C}$
- relative humidity: $20 \%$

- intensity of irradiation (300-400 nm): $75 \mathrm{~W} / \mathrm{m}^{2}$. In the current investigation the specimens were irradiated for 24, 48, 96, 192, and $384 \mathrm{~h}$. After the UVexposure, the specimens were conditioned for approximately $1 \mathrm{~h}$ at $23^{\circ} \mathrm{C}$ and $50 \%$ relative humidity before testing surface tack.

\subsection{Test setup and surface tack investigation}

The requirements for an ideal surface tack measurement were summarized as follows:

- objective measured values instead of human impression

- reproducible and reliable results

- good correlation of test results to human impression of stickiness

- easy to implement on existing equipment

- short measurement times

- flexible in terms of pre-treatment.

After evaluation of different concepts a promising route was identified. The basic idea was to perform a compression-tensile test combination, where a die is first pressed vertically onto the specimen surface with a constant controlled force. After a holding time, the die is detracted at constant pull-off speed, recording the maximum force necessary to remove the die vertically as the surface tack force. This particular procedure of verifying stickiness is similar to the manual assessment according to the Sensotact haptic frame [20].

First of all, the material of the die tip had to be chosen for the further verification of the parameter influences. Since this material is in direct contact with the specimen surface, it should not contain any migrating constituents and have elasticity and softness comparable to a human finger. This should allow the material to adapt completely to a profiled
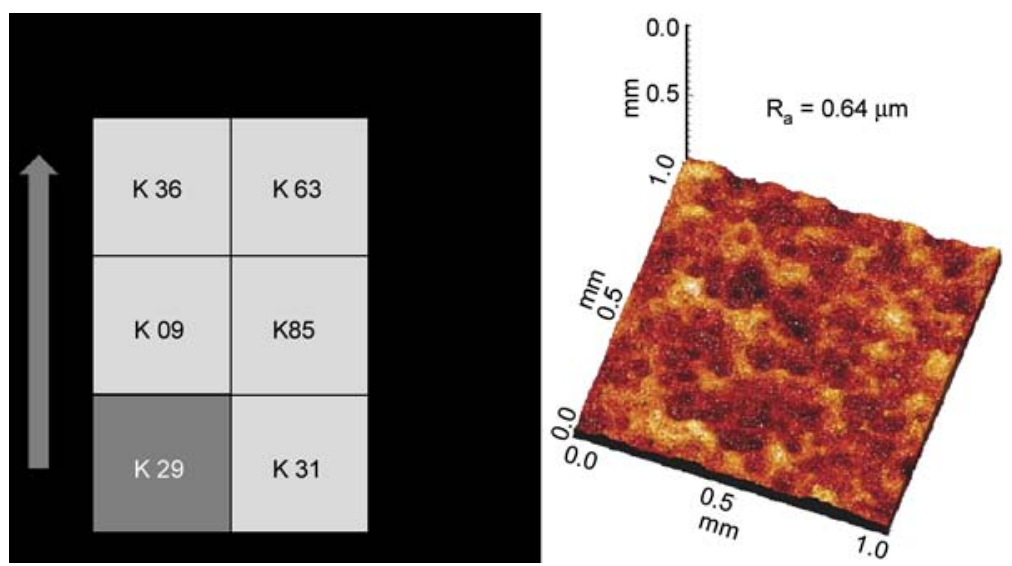

Figure 2. Schematic demonstration of the VW multigrain plaque and topography of the cut-out specimen K29 
surface as typical for automotive interior components while not deforming plastically in the process. Furthermore, it should be easy to process and have good long-term availability. Several materials in a Shore A hardness range from 40 to 70 were screened and a natural rubber/styrene butadiene rubber (NR/ SBR) blend (Semperflex A 560, Semperit Technische Produkte GmbH, Wimpassing, Austria; see [25]) was found to give the best balance between hardness (surface adaptation and 'finger-like' behaviour) and surface tack (no plastic deformation and enhanced adhesion).

An aluminium sheet was chosen as reference surface to be measured prior to each test. The influence of inherent engineering fluctuations of the die tip elastomer on the test result was minimized, and the reproducibility was increased by this procedure. Moreover, to reduce the possibility of transferring surface components from one specimen to another a new die was used for each specimen characterization.

For handling reasons, the elastomer was supplied with a separating agent on its surface which caused large fluctuations in the surface tack test results. In order to minimize the fluctuations, different cleaning conditions using either acetone or water were tested and the standard deviation was monitored. Each cleaning method had several test runs which were compared to a reference non-cleaned elastomer. The acetone cleaned die tips were tested both immediately after cleaning and after $24 \mathrm{~h}$ to verify if there was a change of the elastomer surface (swelling, acetone residuals etc.).

The mechanical properties of the die tip elastomer also change over its lifetime, and the die tip will not show the same behaviour after long time and/or high temperature in surface tack testing. This influence factor was eliminated by using a new elastomer die tip for each measurement, assuming the properties to remain constant for the short testing time window.

In principle, the test setup developed in the present study can be adapted to any tensile testing machine capable of handling the defined test parameters. Figure 3 shows a schematic picture of the setup and a photograph of the installation on the tensile tester. For the current investigations an Instron tensile testing machine (ElectroPuls E3000, Instron Deutschland $\mathrm{GmbH}$; Darmstadt, DEU) was used to perform the experiments.

Each single surface tack measurement was performed with this setup in the following way: After the elastomer (NR/SBR) tip had been cleaned and attached to the die by means of a double-side adhesive tape, the tackiness force $F_{\mathrm{T}}$ of both the aluminium reference and the specimen (sample) were measured. Figure 4 shows an example of the force/ displacement curve from a reference measurement on the aluminium plaque. The tack quotient $Q_{\mathrm{T}}$ was calculated by Equation (1):

$Q_{\mathrm{T}}=\frac{F_{\mathrm{T}, \text { sample }}}{\mathrm{F}_{\mathrm{T}, \text { reference }}}$

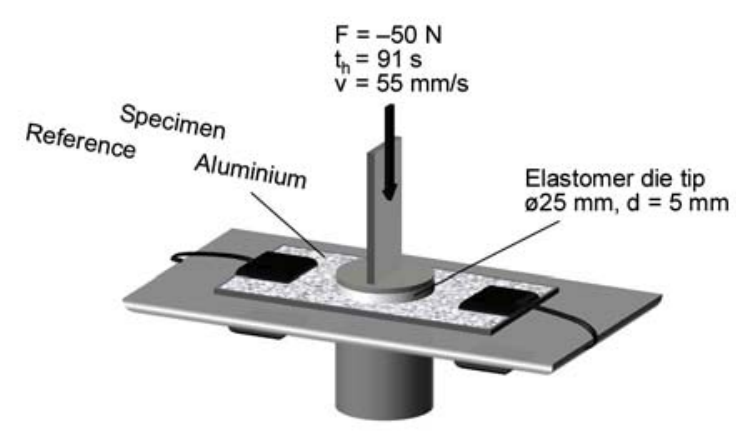

a)

Figure 3. Schematic test setup (a) and photograph of real equipment (b) for surface tack measurements

b)

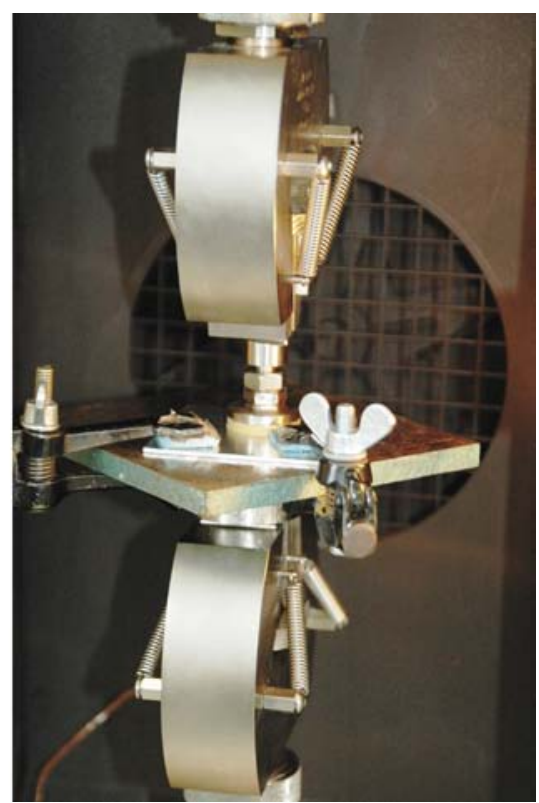




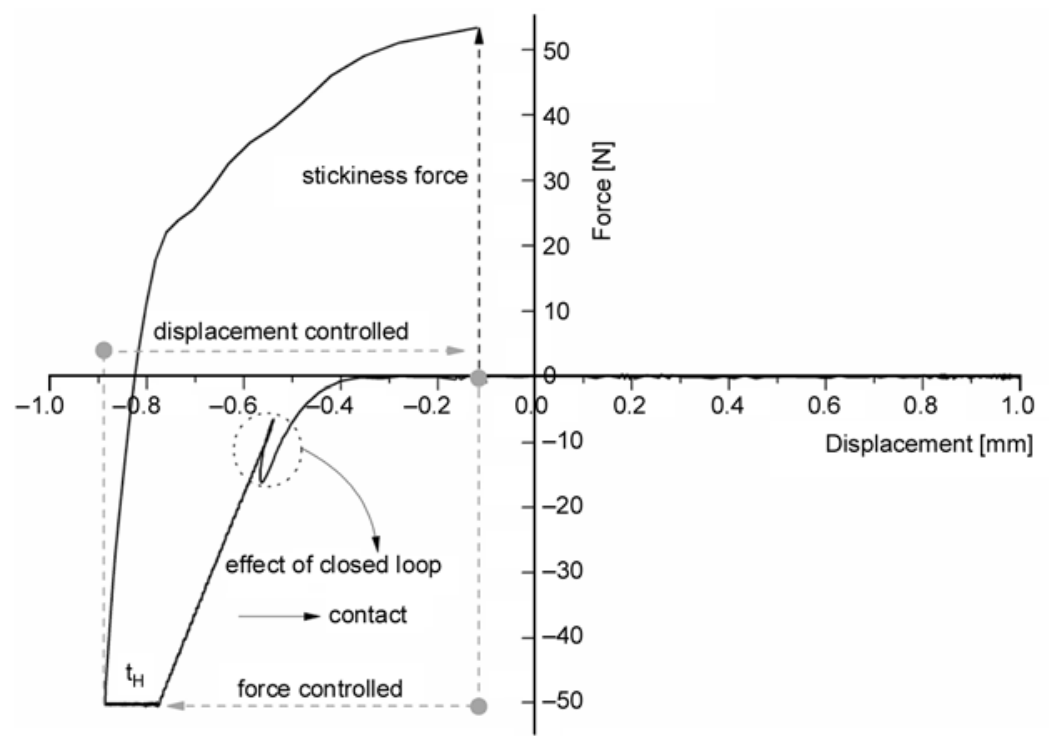

Figure 4. Force / displacement curve from the tack measurement process; the negative displacement shows the compression of the die tip elastomer (tested material: aluminum reference)

and averaged over a minimum of three successive measurements.

\subsection{Test parameter selection and reference}

The main parameters of the stickiness test are the compressive force $(F)$, holding time $\left(t_{\mathrm{H}}\right)$ and hauloff speed $(v)$. A number of other parameters such as environment and specimen clamping were not considered or kept constant during the test. The tests were performed at standard laboratory climate conditions $\left(+23^{\circ} \mathrm{C}\right.$ and $50 \%$ relative humidity). A design of experiments (DoE) was used to determine the effect of the main factors on the measurement, where for each factor two levels were selected.

A DoE with three factors and two levels $\left(2^{3}\right)$ required eight experiments to analyze the significance and effect of each factor (see Table 1). The design of experiments was applied according to Montgomery [26]. The statistical analyses of variances (ANOVA) of the experimental results were examined and the significances of the factors were verified with the aid of the F-test (hypotheses test). The effect of a factor or an interaction (i.e. the combined impact of factors) is the difference in averages between the four treatment combinations at high level minus the average of the four runs where the factor or interaction is at the low level.

A haptic panel according to DIN 10963, which is equivalent to ISO 8587 (2007) [27], was organized
Table 1. Tabulation of performed tests with different levels of the factors according to a 23 design of experiments; $F$ - compressive force, $t_{\mathrm{H}}-$ holding time, $v$ - haul-off speed

\begin{tabular}{|c|c|c|c|}
\hline $\begin{array}{c}\text { Number of } \\
\text { tests }\end{array}$ & $\begin{array}{c}\mathbf{F} \\
{[\mathbf{N}]}\end{array}$ & $\begin{array}{c}\mathbf{t}_{\mathbf{H}} \\
{[\mathbf{s}]}\end{array}$ & $\begin{array}{c}\mathbf{v} \\
{[\mathbf{m m} / \mathbf{s}]}\end{array}$ \\
\hline 1 & -5 & 1 & 10 \\
\hline 10 & -5 & 1 & 100 \\
\hline 5 & -5 & 180 & 10 \\
\hline 7 & -5 & 180 & 100 \\
\hline 8 & -50 & 1 & 10 \\
\hline 6 & -50 & 1 & 100 \\
\hline 4 & -50 & 180 & 10 \\
\hline 2 & -50 & 180 & 100 \\
\hline
\end{tabular}

as reference to verify if the human sense of touch is correlating to the results of the surface tack test. Consisting of about 30 persons of different ages and genders, the testers were trained using a Sensotact tactile frame [20] to assess and rank sticky surfaces and operated at identical environmental conditions as the mechanical test. The fact that the $\mathrm{pH}$-value and the moisture of the testers' fingers also influence their sense of touch was not considered in the haptic panel, and the testers were only instructed to wash their hands. A separate specimen was prepared from each material for each test person. The results of the Friedman-Test show if the same specimens are ranked significantly different by the testers (general difference) and if pairs of specimens are significantly different. 
Table 2. Tack force quotient results from checking the influence of different cleaning conditions of the elastomer die tips

\begin{tabular}{|l|c|c|c|c|}
\hline & Uncleaned & Water & Acetone & Acetone/24 h \\
\hline Measurement 1 & 0.68 & 0.53 & 0.38 & 0.39 \\
\hline Measurement 2 & 0.47 & 0.37 & 0.41 & 0.36 \\
\hline Measurement 3 & 0.30 & 0.44 & 0.35 & 0.36 \\
\hline$Q_{\mathrm{T}}$ average & 0.68 & 0.53 & 0.38 & 0.39 \\
\hline S.dev. $Q_{\mathrm{T}}$ & 0.19 & 0.08 & 0.03 & 0.01 \\
\hline
\end{tabular}

\section{Results and discussion}

\subsection{Cleaning conditions and reproducibility}

The tests performed to select the most appropriate die-tip cleaning conditions were also used to check the reproducibility of the surface tack test. Table 2 summarizes the results of the four series performed with different cleaning conditions, measuring the non-equipped TPO-compound. It shows the clear advantage of acetone as cleaning agent over water, and the rather negligible effect of a waiting period of 24 hours after cleaning, excluding the possible problem of swelling or interaction between acetone and the SBR material.

\subsection{Parameter selection by DoE}

After performing the test series indicated in Table 1 in randomized fashion and identifying both effect level and interaction of the three investigated parameters, it can be deduced that all main and interaction effects are significant for the response value $\left(Q_{\mathrm{T}}\right)$ and thus for the tackiness test. However, the factor $F$ (compressive force) is clearly the most significant factor for the tackiness value. Since the significance of the factors $t_{\mathrm{H}}$ (holding time) and $v$ (haul-off speed) is much lower, the standardized test parameters for the further investigations were defined as factor $F$ at high level, $t_{\mathrm{H}}$ and $v$ at the center level:

- compressive force, $F=-50 \mathrm{~N}$

- holding time, $\quad t_{\mathrm{H}}=91 \mathrm{~s}$

- haul-off speed, $\quad v=55 \mathrm{~mm} / \mathrm{s}$

The test is also illustrated in the force/displacement graph (see Figure 4), where the two phases of the tackiness test and the tackiness force evaluation are shown. The first phase is force controlled at $-50 \mathrm{~N}$ until the holding time (91 s) runs off. During this phase, the die tip elastomer is creeping at constant force. In the second phase, which is displacement controlled $(55 \mathrm{~mm} / \mathrm{s})$ the peak value in the forcedisplacement curve was reported as tackiness force, i.e. force needed to remove the die tip from the specimen's surface.

\subsection{Composition effects and relation to haptic panel results}

Figure 5 summarizes and compares the results from the mechanical tack quotient measurements and the haptic panel ranking for the three investigated compositions. While the correlation appears to be only a qualitative one, the relative ranking of surface tack between the newly developed test method and the established method based on individual human perception is clearly identical. It can therefore be assumed that relative changes in surface tack resulting from variations of polymer composition can be quantified or at least ranked reliably with the new method.

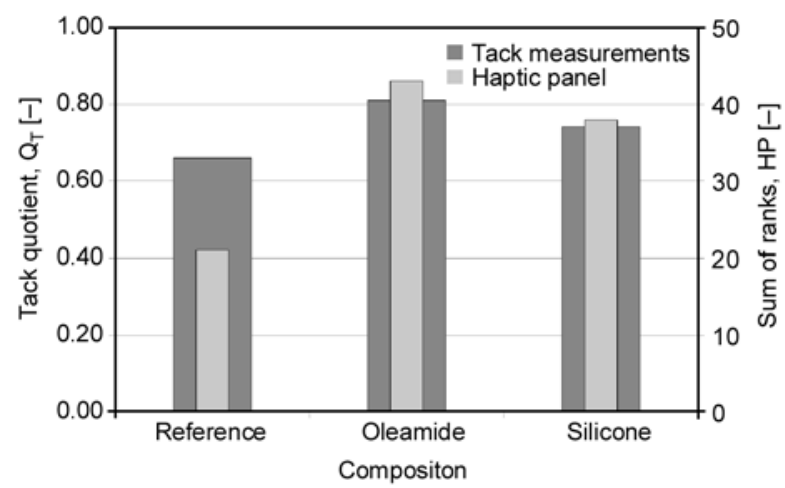

Figure 5. Comparison of results from tack force measurement and haptic panel for the three investigated TPO-compounds with different additivation

\subsection{Weathering effects and time dependence}

The fact that surface tack of polymer components change over times due to migration and ageing effects has been mentioned before. To compare the relative effects for the three investigated compositions, artificial ageing according to the Kalahari weathering conditions in dry and hot climate as defined above were performed. As Figure 6 shows, not only the absolute level of the individual compositions' surface tack, but even the relative ranking changed over time, pointing out the high importance of well defined sample preparation and pretreatment for achieving relevant results. The strong variations at short time for both the reference composition and the one containing the migratory additive (oleamide) probably result from a combination 


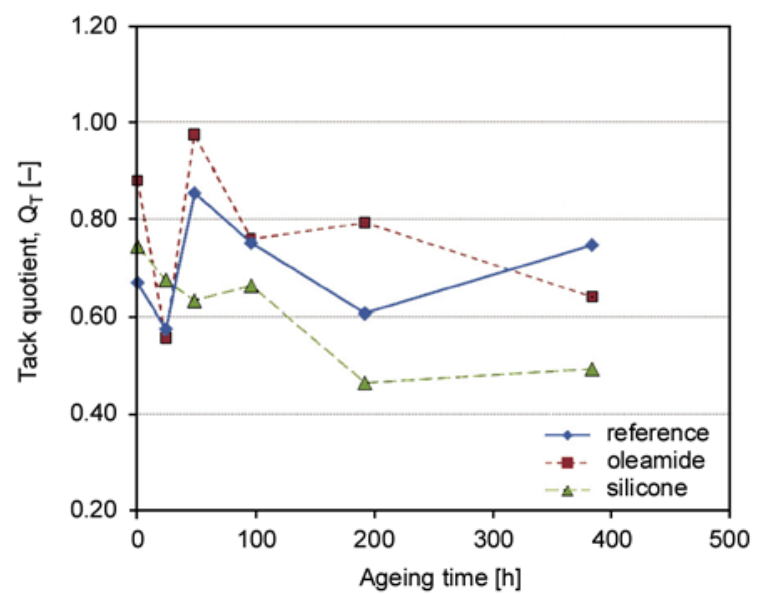

Figure 6. Effect of artificial weathering on the tackiness for the three investigated TPO-compounds with different additivation

of migration and subsequent decomposition of additives. This is in line with experience from haptic panel tests combined with ageing tests before.

\section{Conclusions}

In the present study it could be demonstrated that by means of corresponding development work in the area of measurement methods, it is possible to make very subjective sensory perceptions such as the haptic properties of a surface quantifiable. The key to success lies in breaking down complex sensory perceptions to the most important influencing factors. If this simplification is successful, it is possible to make deductions about the complex human sense of touch also if a very simple test setup is used.

The present results show the possibilities of the developed method, both in respect to comparing different material compositions qualitatively and even (semi-)quantitatively and in assessing the effect of artificial weathering on surface tack. In standard material development this provides a fast method for both assessing the effect of polymer composition variations and different additive formulations. For more complex variations (like massive changes of material mechanics) it will probably still be necessary to reference such results to human perception by involving haptic panel testing.

\section{References}

[1] Karger-Kocsis J., Csikai I.: Skin-core morphology and failure of injection-molded specimens of impact-modified polypropylene blends. Polymer Engineering and Science, 27, 241-250 (1987).

DOI: $10.1002 /$ pen.760270403

[2] Alonso M., Gonzalez A., Requejo A., Arribas M., de Saja J. A.: Air-borne sound absorption and sound speed in talc-filled polypropylene. Polymer Testing, 11, 7178 (1992).

DOI: 10.1016/0142-9418(92)90035-A

[3] Karger-Kocsis J.: Polypropylene: Structure, blends and composites. Vol. 2 - Copolymers and blends. Chapman and Hall, London (1995).

[4] Chu J., Xiang C., Sue H-J., Hollis R. D.: Scratch resistance of mineral-filled polypropylene materials. Polymer Engineering and Science, 40, 944-955 (2000). DOI: $10.1002 /$ pen.11222

[5] Xiang C., Sue H-J., Chu J., Coleman B.: Scratch behavior and material property relationship in polymers. Journal of Polymer Science Part B: Polymer Physics, 39, 47-59 (2001).

DOI: 10.1002/1099-0488(20010101)39:1<47::AIDPOLB50>3.0.CO;2-2

[6] Pasquini N.: Polypropylene handbook. Hanser, Munich (2005).

[7] Koch T., Machl D.: Evaluation of scratch resistance in multiphase PP blends. Polymer Testing, 26, 927-936 (2007).

DOI: $10.1016 / \mathrm{j}$. polymertesting.2007.06.006

[8] Markarian J.: Thermoplastic elastomer compounds continue upward trend. Plastics, Additives and Compounding, 10, 38-43 (2008). DOI: $10.1016 / \mathrm{S} 1464-391 X(08) 70186-7$

[9] Dagman J., Karlsson M. A., Wikström L.: Investigating the haptic aspects of verbalised product experiences. International Journal of Design, 4, 15-27 (2010).

[10] Hamed G. R., Shieh C-H.: Relationship between the cohesive strength and the tack of elastomers. Journal of Polymer Science: Polymer Physics Edition, 21, 14151425 (1983).

DOI: $10.1002 /$ pol.1983.180210812

[11] Voyutskii S. S., Vakula V. L.: The role of diffusion phenomena in polymer-to-polymer adhesion. Journal of Applied Polymer Science, 7, 475-491 (1963).

DOI: 10.1002/app.1963.070070207

[12] Toyama M., Ito T., Moriguchi H.: Studies on tack of pressure-sensitive adhesive tapes. Journal of Applied Polymer Science, 14, 2039-2048 (1970). DOI: 10.1002/app.1970.070140812

[13] Bates R.: Studies in the nature of adhesive tack. Journal of Applied Polymer Science, 20, 2941-2954 (1976). DOI: 10.1002/app.1976.070201102 
[14] Tirumkudulu M., Russel W. B., Huang T. J.: On the measurement of 'tack' for adhesives. Physics of Fluids, 15, 1588-1605 (2003).

DOI: $10.1063 / 1.1571058$

[15] Mith S., Carpentier L., Monteil G.: Correlation between the sensorial perception and the descriptive instrumental analysis of the tackiness of silicone elastomers. Surface and Interface Analysis, 40, 142-145 (2008). DOI: $10.1002 /$ sia.2795

[16] David M. O., Nipithakul T., Nardin M., Schultz J., Suchiva K.: Influence of nonrubber constituents on tack of natural rubber. I. At very short times of contact (pendulum test). Journal of Applied Polymer Science, 78, 1486-1494 (2000).

DOI: $10.1002 / 1097-4628(20001121) 78: 8<1486:: A I D-$

$$
\text { APP40>3.0.CO;2-I }
$$

[17] Smitthipong W., Nardin M., Schultz J., Niphithakul T., Suchiva K.: Study of tack properties of uncrosslinked natural rubber. Journal of Adhesion Science and Technology, 18, 1449-1463 (2004).

DOI: $10.1163 / 1568561042323248$

[18] McNally G. M., Small C. M., Murphy W. R., Garrett G.: The effect of polymer properties on the mechanical behavior and morphological characteristics of cast polyethylene film for stretch and cling film applications. Journal of Plastic Film and Sheeting, 21, 39-54 (2005).

DOI: $10.1177 / 8756087905052804$

[19] Chen X., Shao F., Barnes C., Childs T., Henson B.: Exploring relationships between touch perception and surface physical properties. International Journal of Design, 3, 67-77 (2009).
[20] Legay F.: The first tactile reference frame. Company magazine of CEMAS (Centre of Microtechniques Evaluation dedicated to Sensory Analysis), Besançon (2010).

http://www.sensotact.com

[21] Huber G., Solera P.: New additive to improve scratch resistance and reduce surface tack for automotive applications. in 'Proceedings of the $1^{\text {st }}$ World Automotive Congress-Plastics in Motion, Lisbon, Portugal' p.15 (2006).

[22] Schwager H.: PP reactor blends. in 'Polypropylene ' 92 World Congress, Zürich, Switzerland’ pp. II-4.1II-4.18 (1992).

[23] Eschmann Textures International GmbH: Texture guide- Get in touch. P.19 (2010). http://www.eschmanntextures.de/fileadmin/user upload /downloads/guide/Textures Guide en.pdf

[24] Riedl A.: Überblick über die Methoden der Bewitterungs- und Lichtechtheitsprüfung in der Automobilindustrie (in German). Galvanotechnik, 97, 420427 (2006).

[25] Semperit Technische Produkte GmbH: Semperflex A560, Data sheet (2010). http://www.semperflex.com/uploads/tx_AScatalog/files /A560 e.pdf

[26] Montgomery D. C.: Design and analysis of experiments. Wiley, New York (1991).

[27] ISO 8587: Sensory analysis - Methodology - Ranking (2007). 